\title{
The Universal Transverse Mercator (UTM) Grid
}

\section{Map Projections}

The most convenient way to identify points on the curved surface of the Earth is with a system of reference lines called parallels of latitude and meridians of longitude. On some maps, the meridians and parallels appear as straight lines. On most modern maps, however, the meridians and parallels appear as curved lines. These differences are due to the mathematical treatment required to portray a curved surface on a flat surface so that important properties of the map (such as distance and areal accuracy) are shown with minimum distortion. The system used to portray a part of the round Earth on a flat surface is called a map projection.

\section{Grids}

To simplify the use of maps and to avoid the inconvenience of pinpointing locations on curved reference lines, cartographers superimpose on the map a rectangular grid consisting of two sets of straight, parallel lines, uniformly spaced, each set perpendicular to the other. This grid is designed so that any point on the map can be designated by its latitude and longitude or by its grid coordinates, and a reference in one system can be converted into a reference in another system. Such grids are usually identified by the name of the particular projection for which they are designed.

\section{The Universal Transverse Mercator Grid}

The National Imagery and Mapping Agency (NIMA) (formerly the Defense Mapping Agency) adopted a special grid for military use throughout the world called the Universal Transverse Mercator (UTM) grid. In this grid, the world is divided into 60 north-south zones, each

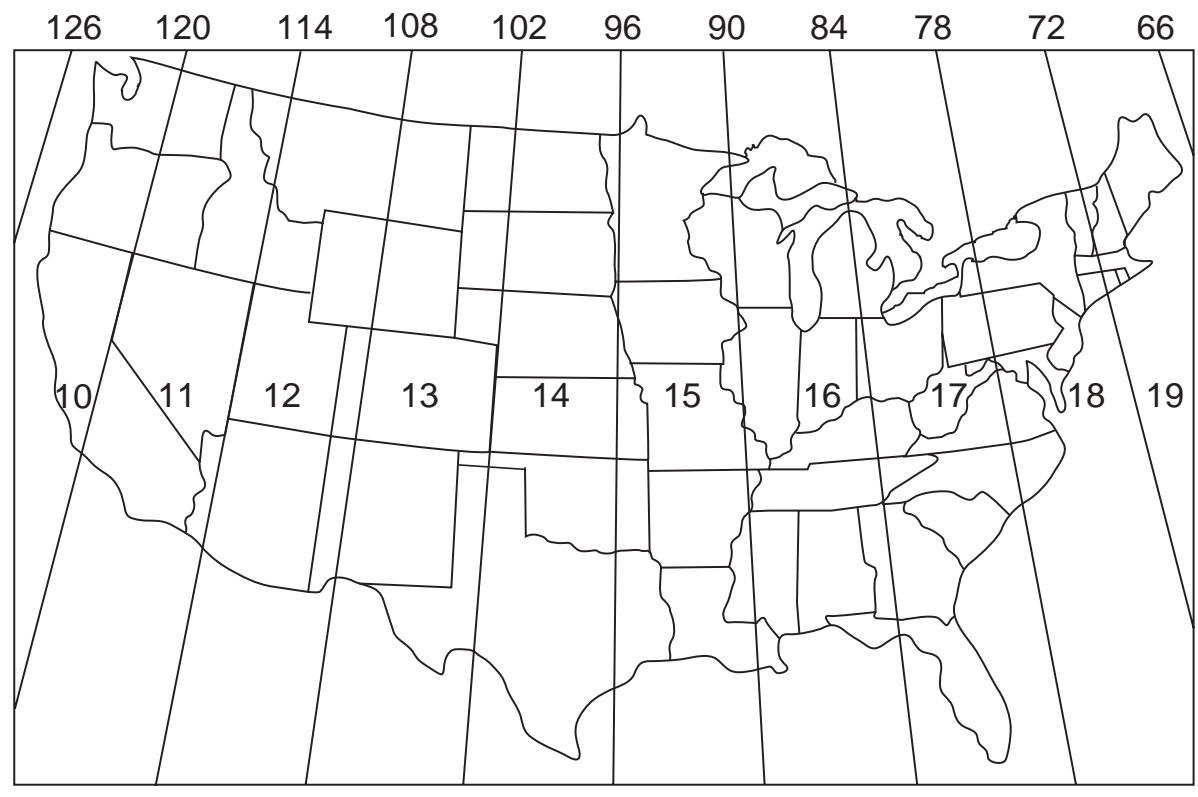

Figure 1. The Universal Transverse M ercator grid that covers the conterminous 48 United States comprises 10 zones- from Zone 10 on the west coast through Zone 19 in New England.

covering a strip $6^{\circ}$ wide in longitude. These zones are numbered consecutively beginning with Zone 1 , between $180^{\circ}$ and $174^{\circ}$ west longitude, and progressing eastward to Zone 60 , between $174^{\circ}$ and $180^{\circ}$ east longitude. Thus, the conterminous 48 States are covered by 10 zones, from Zone 10 on the west coast through Zone 19 in New England (fig. 1). In each zone, coordinates are measured north and east in meters. (One meter equals 39.37 inches, or slightly more than 1 yard.) The northing values are measured continuously from zero at the Equator, in a northerly direction. To avoid negative numbers for locations south of the Equator, NIMA's cartographers assigned the Equator an arbitrary false northing value of $10,000,000$ meters. A central meridian through the middle of each $6^{\circ}$ zone is assigned an easting value of 500,000 meters. Grid values to the west of this central meridian are less than 500,000; to the east, more than 500,000.
Virtually all NIMA-produced topographic maps and many aeronautical charts show the UTM grid lines.

\section{Determining a UTM Grid Value for a Map Point}

The UTM grid is shown on all quadrangle maps prepared by the U.S. Geological Survey (USGS). On 7.5-minute quadrangle maps $(1: 24,000$ and 1:25,000 scale) and 15-minute quadrangle maps (1:50,000, 1:62,500, and standard-edition 1:63,360 scales), the UTM grid lines are indicated at intervals of 1,000 meters, either by blue ticks in the margins of the map or with full grid lines. The $1,000-$ meter value of the ticks is shown for every tick or grid line. In addition, the actual meter value is shown for ticks nearest the southeast and northwest corners of the map. Provisional maps at 1:63,360 scale show full UTM grids at 5,000-meter intervals. 
To use the UTM grid, you can place a transparent grid overlay on the map to subdivide the grid, or you can draw lines on the map connecting corresponding ticks on opposite edges. The distances can be measured in meters at the map scale between any map point and the nearest grid lines to the south and west. The northing of the point is the value of the nearest grid line south of it plus its distance north of that line; its easting is the value of the nearest grid line west of it plus its distance east of that line (see fig. 2).

On maps at 1:100,000 and 1:250,000 scale, a full UTM grid is shown at intervals of 10,000 meters and is numbered and used in the same way.

\section{Information}

For information on these and other USGS products and services, call

1-888-ASK-USGS, use the Ask.USGS fax service, which is available 24 hours a day at 703-648-4888, or visit the general interest publications Web site on mapping, geography, and related topics at mac.usgs.gov/mac/isb/pubs/pubslists/.

For additional information, visit the ask.usgs.gov Web site or the USGS home page at www.usgs.gov.

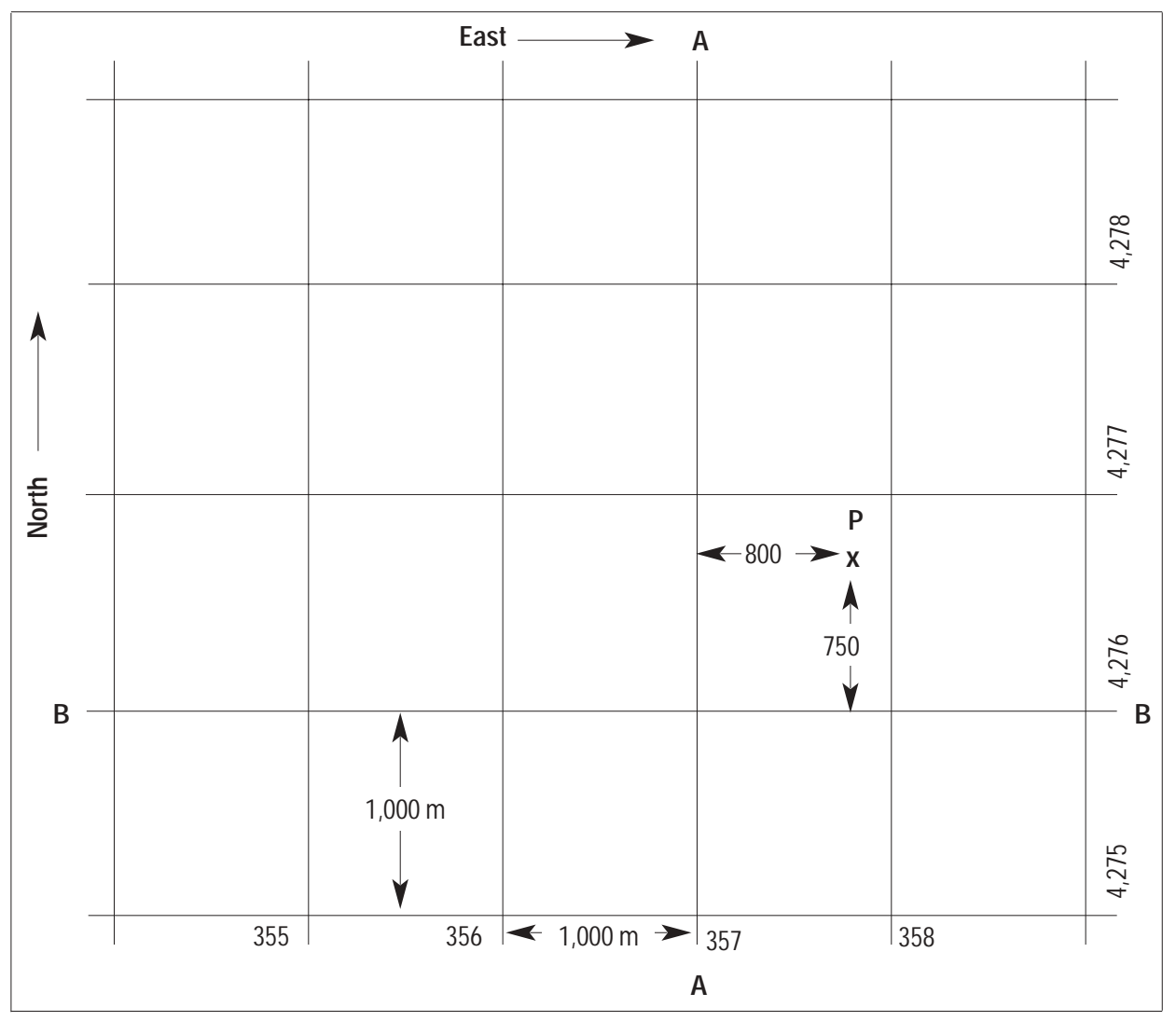

Figure 2. The grid value of line A-A is 357,000 meters east. The grid value of line $B-B$ is $4,276,000$ meters north. $P$ oint $P$ is 800 meters east and 750 meters north of the grid lines; therefore, the grid coordinates of point $P$ are north 4,276,750 and east 357,800. 